\title{
Article
}

\section{A Numerical Study of Chemical Compatibility of GCLs}

\author{
Juan Hou ${ }^{1,2,3, * \mathbb{D}}$, Rui Sun ${ }^{1}$, Chen-Xi Chu ${ }^{1}$, Mpundu Karen ${ }^{1}$ and Marem Nasser ${ }^{1}$ \\ 1 School of Mechanics and Engineering Science, Shanghai University, Shanghai 200444, China; \\ sunrui6@shu.edu.cn (R.S.); chu_chenxi@163.com (C.-X.C.); karenyirenda@gmail.com (M.K.); \\ 7366.marm@gmail.com (M.N.) \\ 2 School of Engineering, University of Virginia, Charlottesville, VA 22904, USA \\ 3 State Key Laboratory of Geomechanics and Geotechnical Engineering, Institute of Rock and Soil Mechanics, \\ Chinese Academy of Sciences, Wuhan 430071, China \\ * Correspondence: juanhou@staff.shu.edu.cn
}

Citation: Hou, J.; Sun, R.; Chu, C.-X.; Karen, M.; Nasser, M. A Numerical Study of Chemical Compatibility of GCLs. Appl. Sci. 2022, 12, 2182. https://doi.org/10.3390/ app12042182

Academic Editor: Xiaowu Tang

Received: 31 December 2021

Accepted: 17 February 2022

Published: 19 February 2022

Publisher's Note: MDPI stays neutral with regard to jurisdictional claims in published maps and institutional affiliations.

Copyright: (C) 2022 by the authors. Licensee MDPI, Basel, Switzerland. This article is an open access article distributed under the terms and conditions of the Creative Commons Attribution (CC BY) license (https:// creativecommons.org/licenses/by/ $4.0 /)$.

\begin{abstract}
A series of COMSOL numerical models were established to study the chemical compatibility of GCLs (geosynthetic clay liner). The effect of chemistry on the mesoscopic structure and the hydraulic conductivity of GCLs was investigated. The factors, including the initial mobile porosity, the swelling ratio, the pore size, and the ionic strength, were discussed as well. The mesoscopic mechanism of the physical and chemical processes of GCLs was explored by the COMSOL models. The hypothesis that the final mobile porosity and the final pore size are the key factors of the hydraulic conductivity of GCLs was proven by the simulation. Meanwhile, when the ionic strength increased from low to medium, the changes in pore size, mobile porosity, and hydraulic conductivity were obvious. However, when the ionic strength increased from medium to high, the changes of these parameters tended to be gentle, and the changes in hydraulic conductivity were not obvious. Moreover, a theoretical model considering the effect of the initial particle size, the initial mobile porosity, and the ionic strength was developed to predict the hydraulic conductivity of GCLs in a chemical solution. This theoretical model was verified by experimental data. A good agreement was obtained.
\end{abstract}

Keywords: chemistry compatibility; COMSOL; mesoscopic mechanism; GCLs; hydraulic performance

\section{Introduction}

Geosynthetic clay liners (GCLs) are factory-manufactured hydraulic barriers consisting of a thin layer of sodium bentonite (Na-B) clay (approximately $3-5 \mathrm{~kg} / \mathrm{m}^{2}$ ) sandwiched between two geotextiles, which are bonded by needle punching or stitching [1]. GCLs are common elements in waste containment facilities because of their low hydraulic conductivity to deionize water (DIW, typically $<10^{-10} \mathrm{~m} / \mathrm{s}$ ) [1-5].

Chemical compatibility is generally defined as the degree of change in the engineering properties of the barrier due to its exposure to contaminants [6]. Jo [7] and Kolstad [3] demonstrated that ionic strength is the main variable affecting the hydraulic conductivity of bentonite in GCLs. However, the mesoscopic structure effect of a chemical solution on the permeability of GCLs is difficult to be observed in the experiments. Many kinds of research have shown that the hydraulic conductivity of GCLs depends on the mobile porosity (or the mobile water) [8-12], which is sensitive to the chemical solution [13-15]. However, a direct translation of X-ray data to GCLs is difficult because GCLs are multi-component systems [16-18]. Meanwhile, the porosity estimates for GCLs depend on subtle interactions within the pore spaces governed by the leachate flux process [19-21]. At present, few studies have focused on the mesoscopic mechanism of hydration and swelling under the effect of inorganic chemical solutions. Therefore, the influence of chemistry on the mesoscopic structure and the permeability of GCLs needs to be assessed [22,23].

The finite-element COMSOL Multiphysics software is very convenient to simulate and analyze the infiltration process of GCLs [24-26]. In this work, we will establish a 
COMSOL numerical model to study the anti-seepage performance of bentonite components. The swelling and permeation process of GCLs in a chemical solution will be simulated as well. The effects of the initial mobile porosity, the swelling ratio, the pore size, and the chemical compatibility of GCLs were studied.

Figure 1 gives the flow chart of this paper. Firstly, a series of COMSOL models which simulate the GCLs in DIW were established. Based on these numerical models, an equation, including the final mobile porosity, the initial mobile porosity, and the initial particle size for calculating the hydraulic conductivity of GCLs, was proposed. Secondly, the final mobile porosity was expressed by the hydraulic conductivity, the initial mobile porosity, and the initial particle size. Using the fitting method and experimental data, a relationship between the final mobile porosity and the ionic strength was obtained. Finally, a series of COMSOL models were established to investigate the chemical compatibility of GCLs. The mesoscopic mechanism of the physical and chemical processes was screened in COMSOL models. Based on the numerical simulation, a theoretical model which can predict the hydraulic conductivity of GCLs in a chemical solution was proposed.

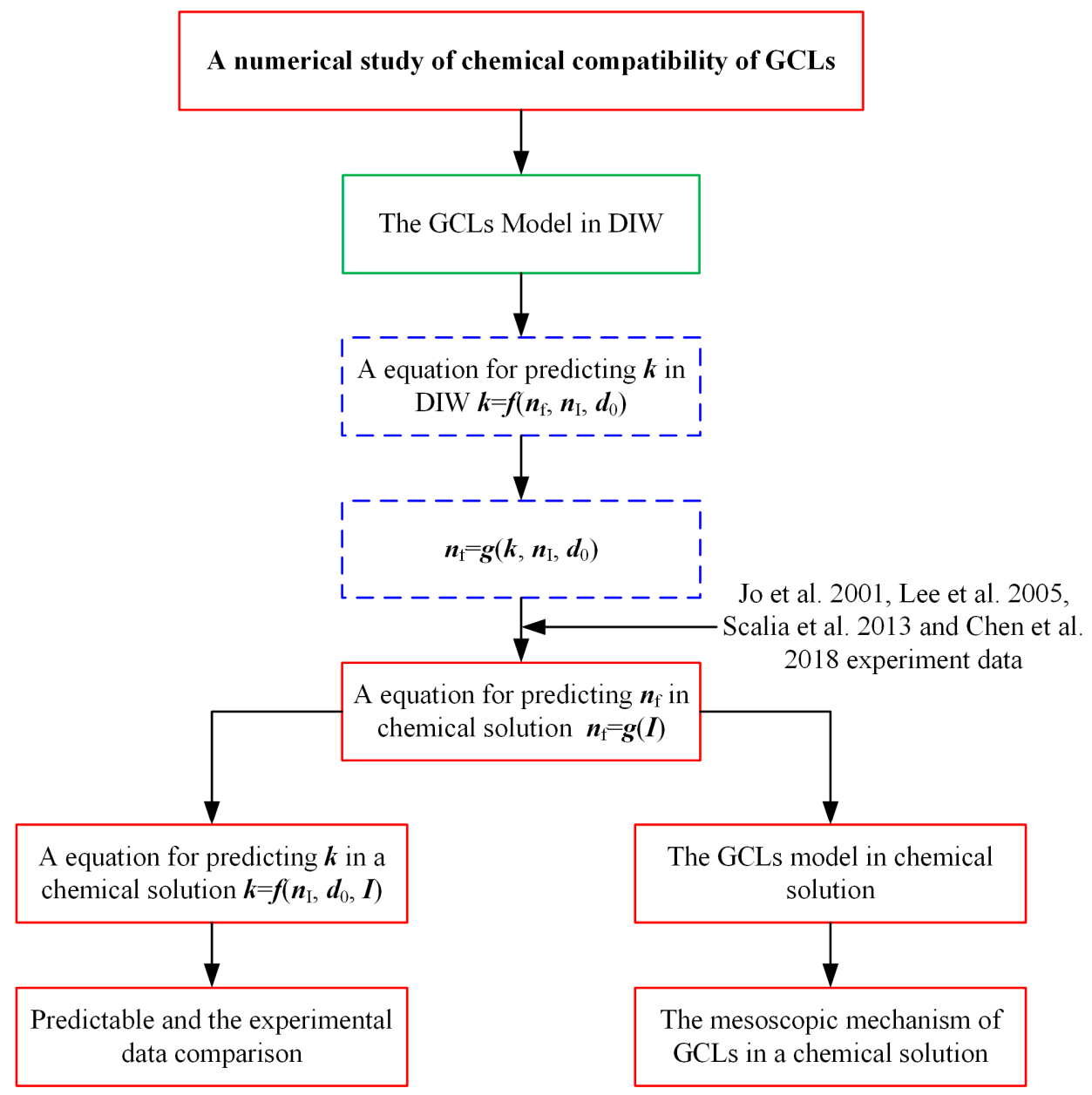

Figure 1. Flowchart for studying the mesoscopic mechanism of GCLs in a chemical solution.

\section{COMSOL Numerical Model}

In general, the solution process of COMSOL Multiphysics [26] is divided into four steps: (1) Establishing a geometric model; (2) Defining the physical fields; (3) Mesh generated and solving; (4) Visual post-processing. The water in bentonite can be partitioned into two fractions: mobile porewater that flows readily in the pore space and immobile porewater that is bound electrically through electrical interactions between polar water molecules, ions dissolved in the water, and the pore space $[8,9,27]$. It should be noted that in the GCLs permeation tests, the bentonite is in full saturation under a constant confine 
pressure (ASTM D6766). In this condition, the pore size and the mobile porosity related to the mobile water are the key parameters affecting the hydraulic conductivity. Therefore, moisture penetration, moisture diffusion, and the intermolecular bonding force are not considered in the flow function.

\subsection{Geometric Model}

The researches of Liu [28], Bian [29], and Ren [30] showed that the pore size is less than $0.1 \mathrm{~mm}$ when the GCLs have low hydraulic conductivity to water (typically $<10^{-10} \mathrm{~m} / \mathrm{s}$ ). Some results indicated that the total void ratio of hydrated GCLs is essentially equivalent to that of the bentonite component only because the bentonite fills all geotextile void spaces [31]. Regarding these researchers [28-30], a model as shown in Figure 2 is developed, in which the grey region represents the bentonite particles, and the blue region represents the permeating solution.

According to Darcy's law, the hydraulic conductivity of GCLs is theoretically not affected by the hydraulic gradient [32]. Therefore, for the sake of calculation efficiency, the inlet and outlet pressure were set to $1 \mathrm{~Pa}$ and $0 \mathrm{~Pa}$, respectively. Meanwhile, considering the Reynolds number was much less than 1 in the GCLs, the inlet and outlet were set to fully developed flow accordingly.

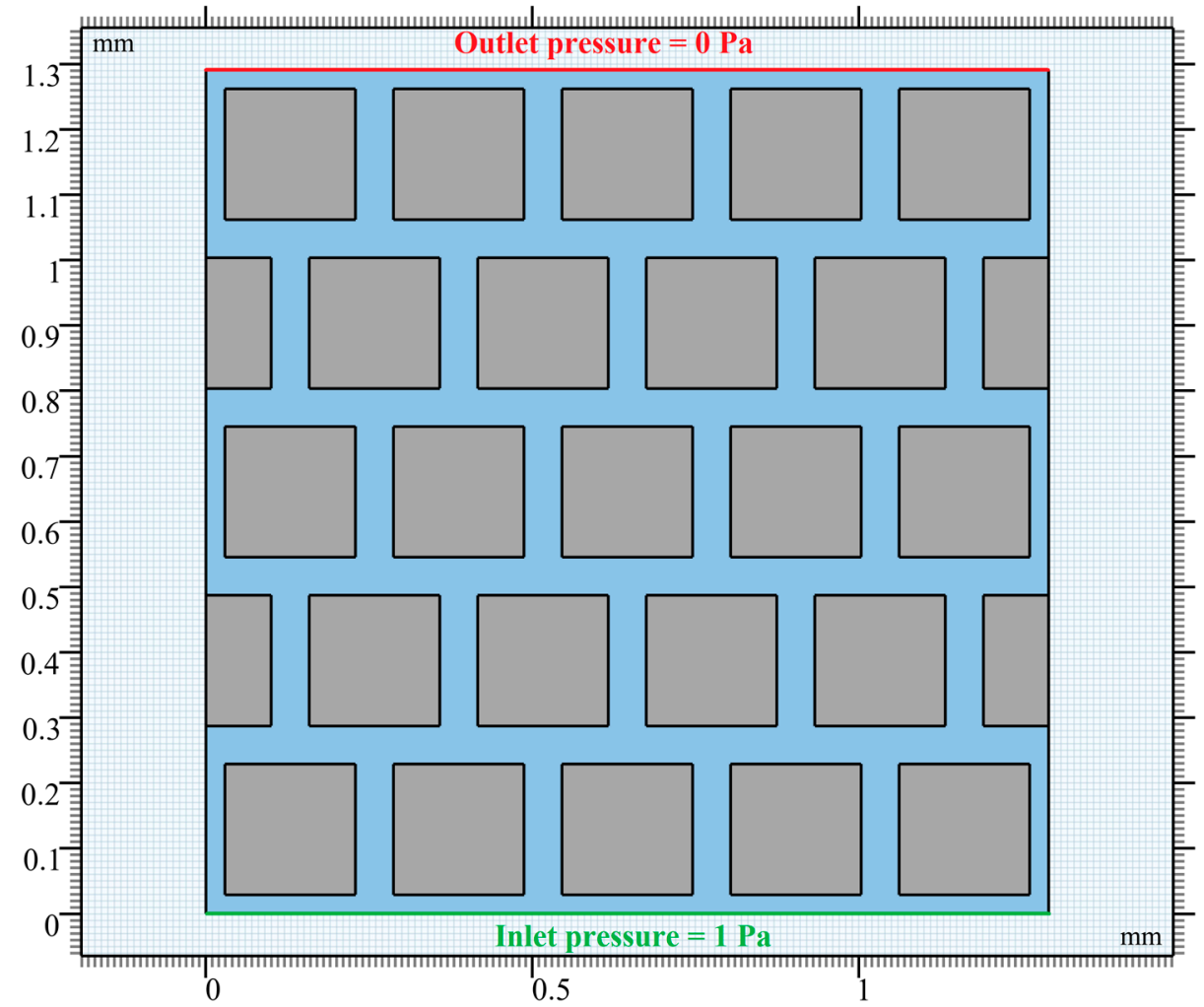

Figure 2. COMSOL basic geometric model (grey region: bentonite; blue region: chemical solution).

\subsection{The Physical Field}

In the GCLs, the bentonite is in a fully saturated state [33]. Therefore, there are only solid and liquid phases. In COMSOL, the fluid in the pores of the particles is regarded as an incompressible flow and can be expressed by the Navier-Stokes equation [34,35]. Meanwhile, the fluid is the creeping flow, and the temperature is constant during the tests. Consequently, the Navier-Stokes equation can be simplified without considering the non-isothermal flow and can be expressed as follows:

$$
\frac{\partial \rho}{\partial t}+\nabla \cdot(\rho u)=0
$$




$$
0=\nabla \cdot[-p T+\tau]+F
$$

where: $\rho$ is the density $\left(\mathrm{kg} / \mathrm{m}^{3}\right) ; u$ is the velocity vector $(\mathrm{m} / \mathrm{s}) ; p$ is the pressure $(\mathrm{Pa}) ; T$ is the unit second-order tensor; $\tau$ is the viscous stress tensor (Pa); $F$ is the volume force vector $\left(\mathrm{N} / \mathrm{m}^{3}\right)$.

The average velocity of the outlet is obtained by dividing the volumetric flow rate over the total cross-sectional area of the model on the $y$-axis. The hydraulic conductivity of GCLs, therefore, can be calculated according to Darcy's law:

$$
k=\frac{v}{i}
$$

where $k$ is the hydraulic conductivity of GCLs, $v$ is the average velocity of the outlet, $I$ is the hydraulic gradient.

\subsection{Mesh Generated and Solving}

Regarding the study of Zimmerman [36], the mesh was 98,218 triangular units (Figure 3). The mesh was composed of "extremely fine" elements, including 93,502 triangular units and 4716 quadrilateral units. The mesh had 54,361 verticals, 5832 edge elements, and 112 vertex elements.
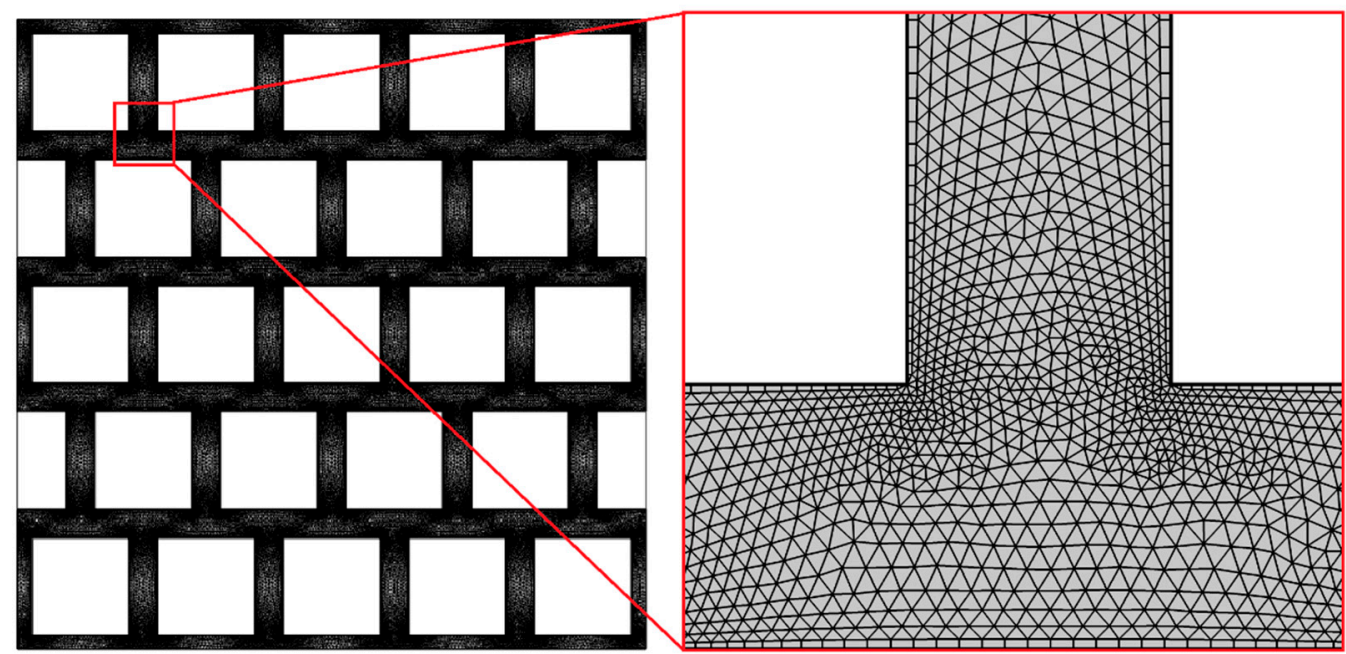

Figure 3. Finite element grid.

The solving steps of the COMSOL numerical model were as follows:

Firstly, the COMSOL model was built. The initial mobile porosity could be calculated by:

$$
n_{\mathrm{I}}=\frac{A_{\mathrm{s}}-A_{\mathrm{pI}}}{A_{\mathrm{s}}}
$$

where $n_{\mathrm{I}}$ is the initial mobile porosity. $A_{\mathrm{S}}$ is the area of the sample. $A_{\mathrm{pI}}$ is the initial area of the total particles.

The final mobile porosity could be calculated as follows:

$$
n_{\mathrm{f}}=\frac{A_{\mathrm{s}}-A_{\mathrm{pf}}}{A_{\mathrm{s}}}
$$

where $n_{\mathrm{f}}$ is the final mobile porosity. $A_{\mathrm{pf}}$ is the final area of the total particles.

The swelling ratio could be calculated as follows:

$$
R_{\mathrm{s}}=\frac{A_{\mathrm{pf}}-A_{\mathrm{pI}}}{A_{\mathrm{pI}}}
$$


where $R_{\mathrm{s}}$ is the swelling ratio.

The pore size is the distance between two particles in a row.

Secondly, changing the particle areas and calculating the mobile porosity, a new COMSOL model with a new particles size and pore size was built again. The final mobile porosity, the swelling ratio, and the pore size could be calculated accordingly.

Finally, by repeating the above two processes, all data in this research could be obtained.

\section{The Numerical Results and Discussion}

\subsection{An Equation for Calculating the Hydraulic Conductivity of GCLs under DIW}

12 conditions with different particle sizes and initial mobile porosity were considered. Twelve COMSOL models that represent the GCLs under DIW were developed and calculated. All the cases are summarized in Table 1.

Table 1. Summary of Working Conditions in DIW.

\begin{tabular}{ccccc}
\hline \multirow{2}{*}{$\begin{array}{c}\text { The Initial } \\
\text { Mobile Porosity }\end{array}$} & \multicolumn{5}{c}{ The Particle Size (mm) } \\
\cline { 2 - 5 } & $\mathbf{0 . 0 2}$ & $\mathbf{0 . 0 8}$ & $\mathbf{0 . 2}$ & $\mathbf{1 . 0}$ \\
\hline 0.4 & 1 & 1 & 1 & 1 \\
0.5 & 1 & 1 & 1 & 1 \\
0.6 & 1 & 1 & 1 & 1 \\
\hline
\end{tabular}

Figure 4 illustrates the relationship between hydraulic conductivity and mobile porosity $\left(n_{\mathrm{M}}\right)$. It can be seen that the hydraulic conductivity decreased with the decrease in the mobile porosity. When the final mobile porosity was archived $\left(n_{\mathrm{f}}=0.025\right.$ here), selecting the final conditions of 12 cases (all the leftmost points in Figure 4), the data of 12 points corresponding to $n_{\mathrm{f}}=0.025 \mathrm{can}$ be obtained. These relationships between the hydraulic conductivity and the final mobile porosity $\left(n_{\mathrm{f}}=0.025\right)$ were illustrated in Figure 5 (see three triangle symbols).

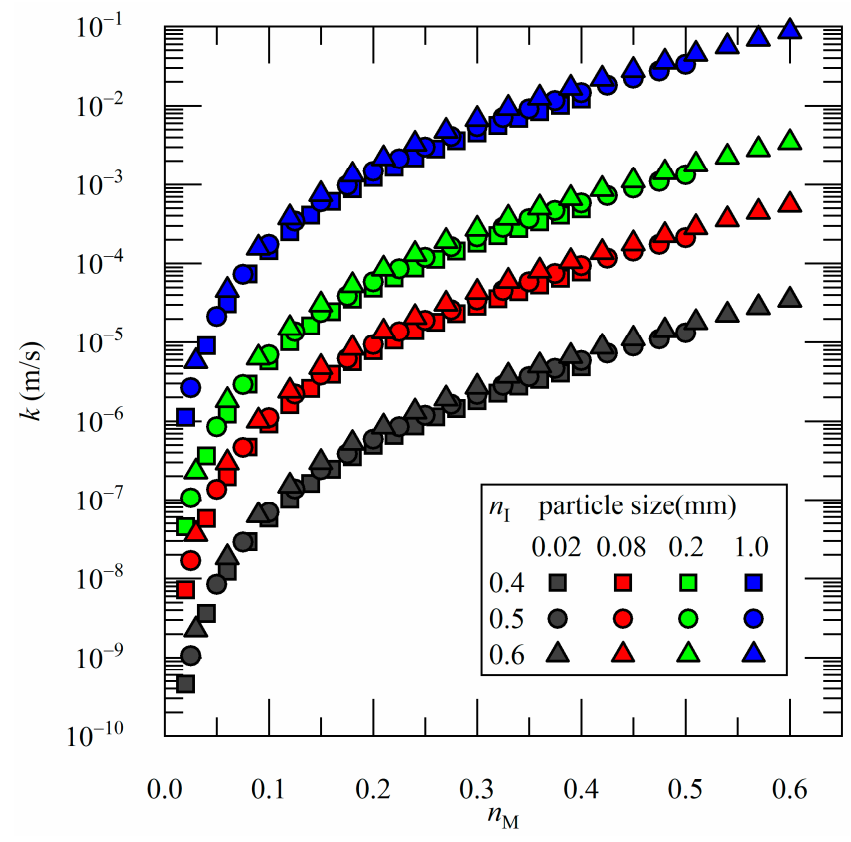

Figure 4. Relationship between hydraulic conductivity and the mobile porosity $\left(n_{\mathrm{f}}=0.025\right)$. 


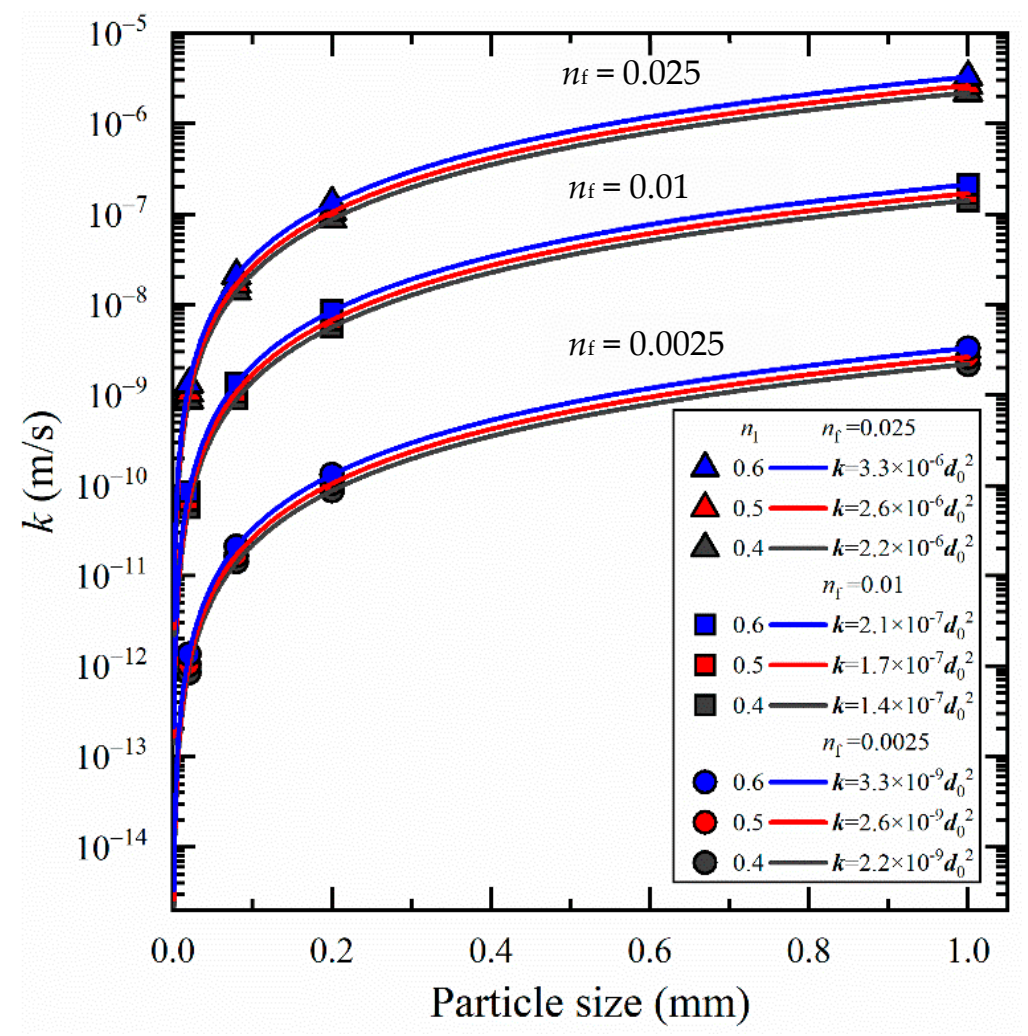

Figure 5. The hydraulic conductivity vs. the mobile porosity.

The final mobile porosity was then changed to 0.01 and 0.0025 , respectively. Following the same steps as above, the data of the other 24 points correspond to $n_{\mathrm{f}}=0.01$, and $n_{\mathrm{f}}=0.0025$, as shown in Figure 5, could be obtained.

By fitting the data in Figure 5, the relationship between $k$ and $d_{0}$ as follows can be obtained:

$$
k=\beta d_{0}^{2}
$$

where $\beta$ is a coefficient; $d_{0}$ is the initial particle size $(\mathrm{mm})$.

As can be seen from Equation (7), the hydraulic conductivity was quadratic dependent on the particle size. This is consistent with those of Mcdowell and Liu [37-39].

Meanwhile, there was a relationship between the coefficient $\beta$ and the final and the initial mobile porosity, as shown in Table 2 according to the COMSOL models.

Table 2. $\beta$ corresponds to the final and initial mobile porosity.

\begin{tabular}{ccc}
\hline$n_{\mathbf{f}}$ & $\boldsymbol{n}_{\mathbf{0}}$ & $\boldsymbol{\beta}$ \\
\hline 0.025 & 0.4 & $2.2 \times 10^{-6}$ \\
0.025 & 0.5 & $2.6 \times 10^{-6}$ \\
0.025 & 0.6 & $3.3 \times 10^{-6}$ \\
0.01 & 0.4 & $1.4 \times 10^{-7}$ \\
0.01 & 0.5 & $1.7 \times 10^{-7}$ \\
0.01 & 0.6 & $2.1 \times 10^{-7}$ \\
0.0025 & 0.4 & $2.2 \times 10^{-9}$ \\
0.0025 & 0.5 & $2.6 \times 10^{-9}$ \\
0.0025 & 0.6 & $3.3 \times 10^{-9}$ \\
\hline
\end{tabular}

Therefore, using the fitting method, the coefficient $\beta$ can be expressed by the flowing equation:

$$
\beta=0.1114\left(n_{\mathrm{f}}\right)^{3}+0.4589\left(n_{\mathrm{f}}\right)^{3} n_{\mathrm{I}}^{3}
$$

where $n_{\mathrm{f}}$ is the final mobile porosity; $n_{\mathrm{I}}$ is the initial mobile porosity. 
Substitute Equation (8) into Equation (7), the following equation can be obtained:

$$
k=\left(0.1114\left(n_{\mathrm{f}}\right)^{3}+0.4589\left(n_{\mathrm{f}}\right)^{3} n_{0}^{3}\right) d_{0}^{2}
$$

where $k$ is the hydraulic conductivity $(\mathrm{m} / \mathrm{s})$.

When the final mobile porosity varies from 0.0025 to 0.025 [40,41], considering the initial mobile porosity and the initial particle size, Formula (9) for calculating the hydraulic conductivity of GCLs in DIW could be obtained.

Therefore, the final mobile porosity can be expressed as follows:

$$
n_{\mathrm{f}}=\sqrt[3]{\frac{k}{\left(0.1114+0.4589 n_{0}^{3}\right) d_{0}^{2}}}
$$

\subsection{An Equation for Calculating the Hydraulic Conductivity of GCLs under Chemical Solution}

Jo [2], Lee [42], Scalia [43], Chen [44] investigated the chemical compatibility of GCLs experimentally. The experimental data are summarized in Table 3. The concentration of the chemical solution could be expressed as the ionic strength (I) [3].

\begin{tabular}{|c|c|c|c|c|}
\hline Literature & $\begin{array}{c}\text { Initial Particle } \\
\text { Size }\left(d_{0}\right) / \mathrm{mm}\end{array}$ & $\begin{array}{c}\text { Initial Mobile } \\
\text { Porosity }\left(n_{0}\right)\end{array}$ & $\begin{array}{l}\text { Chemical } \\
\text { Solution }\end{array}$ & $\begin{array}{c}\text { Ionic Strength } \\
(\mathrm{mol} / \mathrm{L})\end{array}$ \\
\hline \multirow{12}{*}{ Jo [2] } & \multirow{12}{*}{0.5} & \multirow{12}{*}{0.416} & $0.1 \mathrm{M} \mathrm{NaCl}$ & 0.1 \\
\hline & & & $1.0 \mathrm{M} \mathrm{NaCl}$ & 1.0 \\
\hline & & & $0.1 \mathrm{M} \mathrm{KCl}$ & 0.1 \\
\hline & & & $1.0 \mathrm{M} \mathrm{KCl}$ & 1.0 \\
\hline & & & $0.025 \mathrm{M} \mathrm{MgCl}_{2}$ & 0.015 \\
\hline & & & $0.1 \mathrm{M} \mathrm{MgCl}_{2}$ & 0.3 \\
\hline & & & $1 \mathrm{M} \mathrm{MgCl}_{2}$ & 3 \\
\hline & & & $0.1 \mathrm{M} \mathrm{ZnCl}_{2}$ & 0.3 \\
\hline & & & $1.0 \mathrm{M} \mathrm{ZnCl}_{2}$ & 3 \\
\hline & & & $0.01 \mathrm{M} \mathrm{LaCl}_{3}$ & 0.06 \\
\hline & & & $0.025 \mathrm{M} \mathrm{LaCl}_{3}$ & 0.15 \\
\hline & & & $0.1 \mathrm{M} \mathrm{LaCl}_{3}$ & 0.6 \\
\hline \multirow{4}{*}{ Lee [42] } & \multirow{4}{*}{0.5} & \multirow{4}{*}{0.4} & $0.005 \mathrm{M} \mathrm{CaCl}_{2}$ & 0.015 \\
\hline & & & $0.01 \mathrm{M} \mathrm{CaCl}_{2}$ & 0.03 \\
\hline & & & $0.1 \mathrm{M} \mathrm{CaCl}_{2}$ & 0.3 \\
\hline & & & $0.5 \mathrm{M} \mathrm{CaCl}_{2}$ & 1.5 \\
\hline \multirow{3}{*}{ Scalia [43] } & \multirow{3}{*}{0.5} & \multirow{3}{*}{0.4} & $0.02 \mathrm{M} \mathrm{CaCl}_{2}$ & 0.06 \\
\hline & & & $0.05 \mathrm{M} \mathrm{CaCl}_{2}$ & 0.15 \\
\hline & & & $0.2 \mathrm{M} \mathrm{CaCl}_{2}$ & 0.6 \\
\hline \multirow{5}{*}{ Chen [44] } & \multirow{2}{*}{1} & \multirow{2}{*}{0.5} & - & 0.0395 \\
\hline & & & . & 0.0968 \\
\hline & \multirow{3}{*}{0.3} & \multirow{3}{*}{0.5} & - & 0.048 \\
\hline & & & - & 0.178 \\
\hline & & & - & 0.755 \\
\hline
\end{tabular}

Table 3. The experimental hydraulic conductivity of the GCLs [2,42-44].

Substituting the experimental hydraulic conductivity data, the initial particle size, and the initial mobile porosity of Jo [2], Lee [42], Scalia [43], Chen [44] into Formula (8), the final mobile porosity could be obtained. Therefore, the relationship between the final mobile porosity required to reach the experimental hydraulic conductivity and the ionic strength could be plotted as shown in Figure 6. 


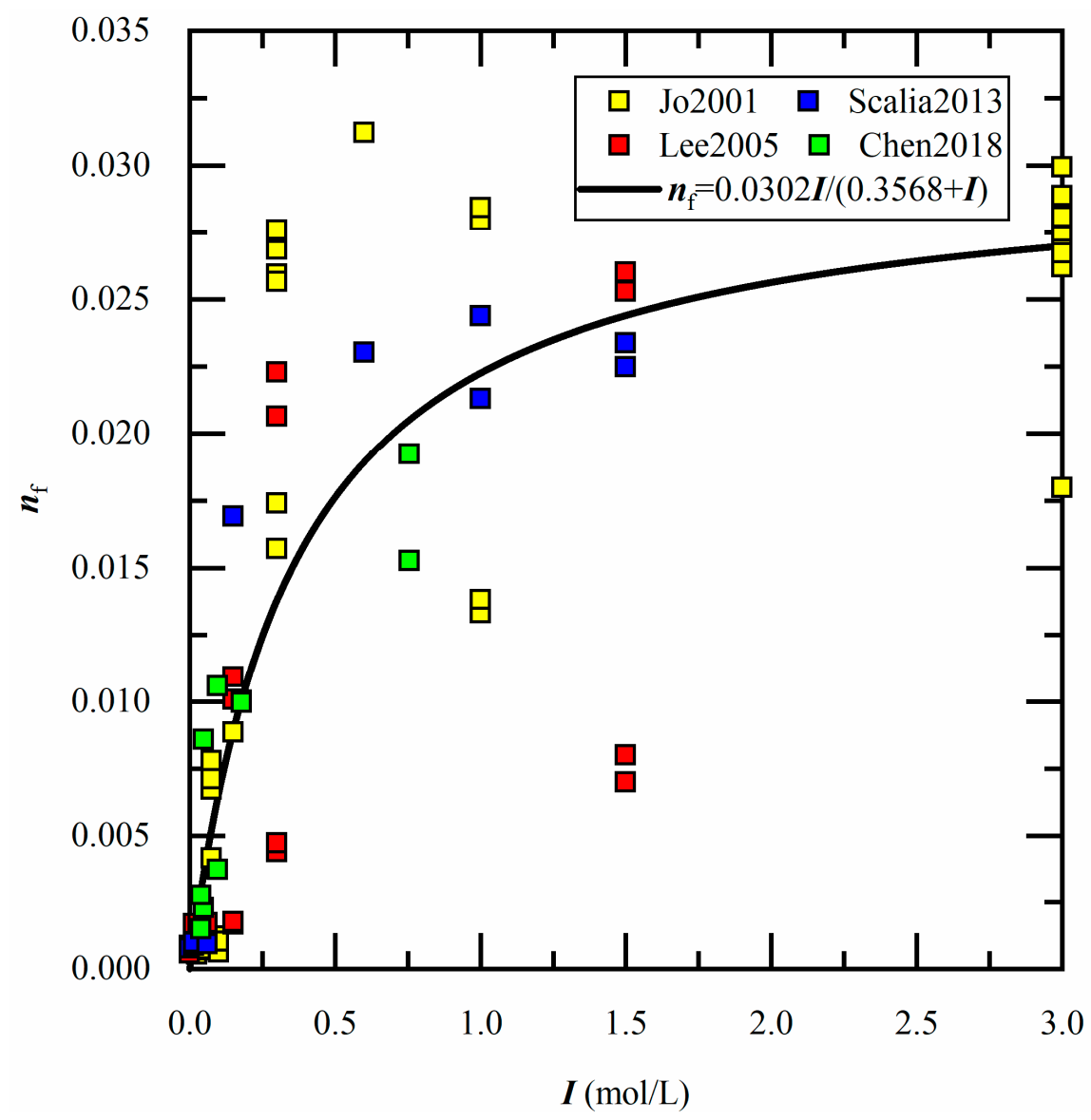

Figure 6. Relationship between final mobile porosity and Ionic strength.

It can be seen that with the increase in ionic strength, the hydraulic conductivity of GCLs showed an upward trend, indicating that the ionic strength and mobile porosity $n_{\mathrm{f}}$ have a very strong relationship (see symbols in Figure 6). Using the fitting method (see the solid curve in Figure 6), the relationship between the final mobile porosity and the ionic strength could be fitted, and the formula could be obtained as follows:

$$
n_{\mathrm{f}}=\frac{0.0302 I}{0.3568+I}
$$

Substituting Equation (11) into Equation (9), the hydraulic conductivity of GCLs in a chemical solution could be expressed as follows:

$$
k=\left(0.1114\left(\frac{0.0302 I}{0.3568+I}\right)^{3}+0.4589\left(\frac{0.0302 I}{0.3568+I}\right)^{3} n_{0}^{3}\right) d_{0}^{2}
$$

Figure 7 illustrates the relationship between the final mobile porosity with the hydraulic conductivity of GCLs, which was calculated from Equation (12). All the data came from Jo [2], Lee [42], Scalia [43], and Katsumi [6]. It can be seen that the hydraulic conductivity decreased with the decrease in mobile porosity significantly. 


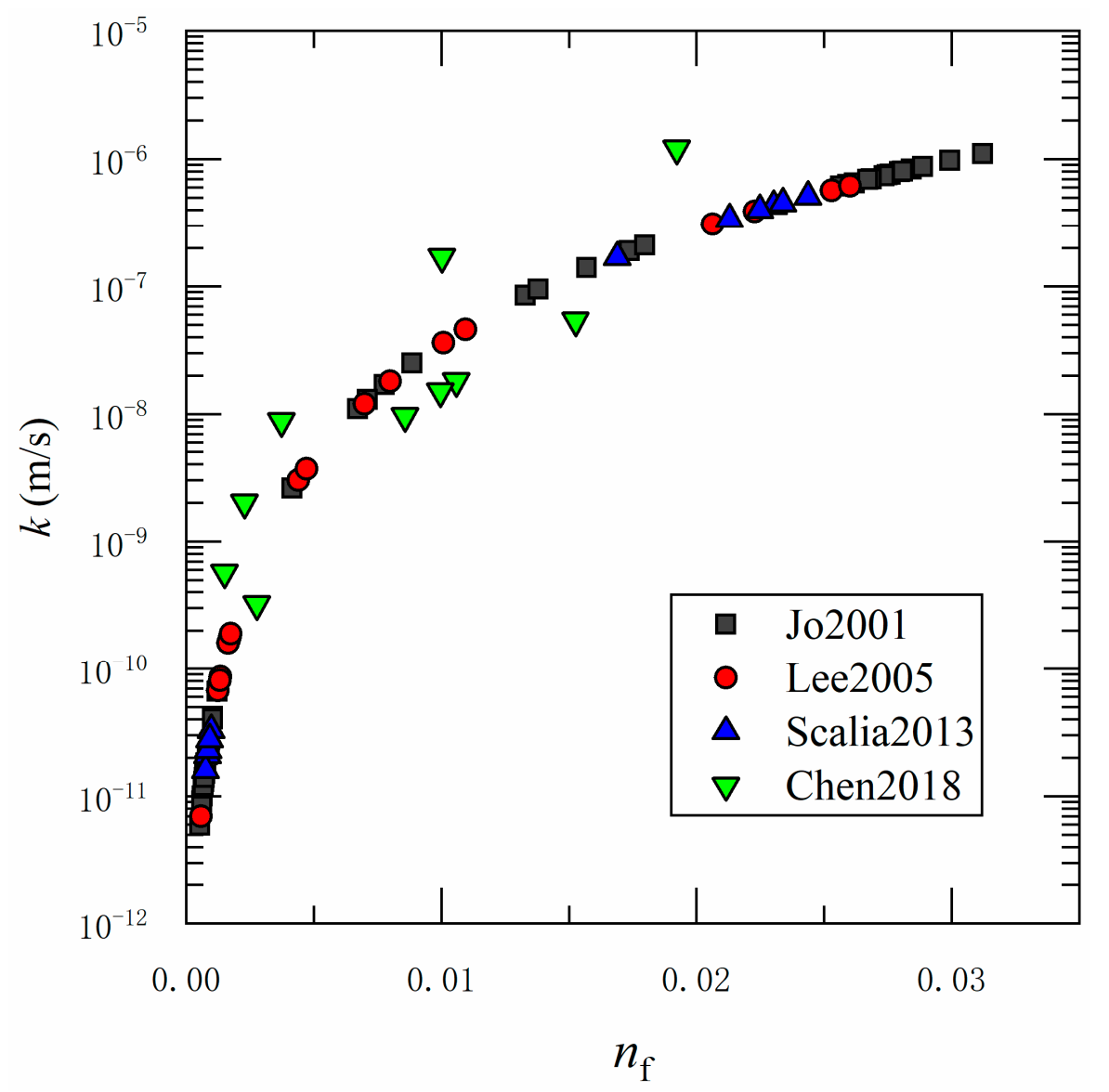

Figure 7. The hydraulic conductivity vs. the mobile porosity.

Therefore, using Equation (12), a series of the COMSOL model can be developed to investigate the mesoscopic mechanism of chemical compatibility of GCLs in detail. The next section will discuss this mesoscopic mechanism using Katsumi's data as an example [6].

\subsection{The Mesoscopic Mechanism of GCLs under Chemical Solution}

GCLs is chemical compatible with liquid to be contained if the hydraulic conductivity of the GCLs remains sufficiently low for the intended application when the GCLs is in chemical equilibrium with the liquid. However, the mechanism of the chemical compatibility of GCLs is difficult to be investigated in a hydraulic conductivity test. Therefore, from the mesoscopic view, the influence of flow path, the pore size, and the mobile porosity on the chemical compatibility and the hydraulic conductivity of GCLs need to be further investigated. Figure 8 illustrates a typical COMSOL model with the initial particle size is $0.075 \mathrm{~mm}$, the initial mobile porosity is 0.4 , and the ionic strength is 0 to $0.5 \mathrm{~mol} / \mathrm{L}$. Concerning the final mobile porosity and the final pore size changes, the influence of the ionic strength on the hydraulic conductivity of GCLs was explored. The chemical compatibility of GCLs was discussed. All these data were consistent with the experimental data of Katsumi [6]. This model could screen the effect of the chemical solution and mesoscopic mechanism. 


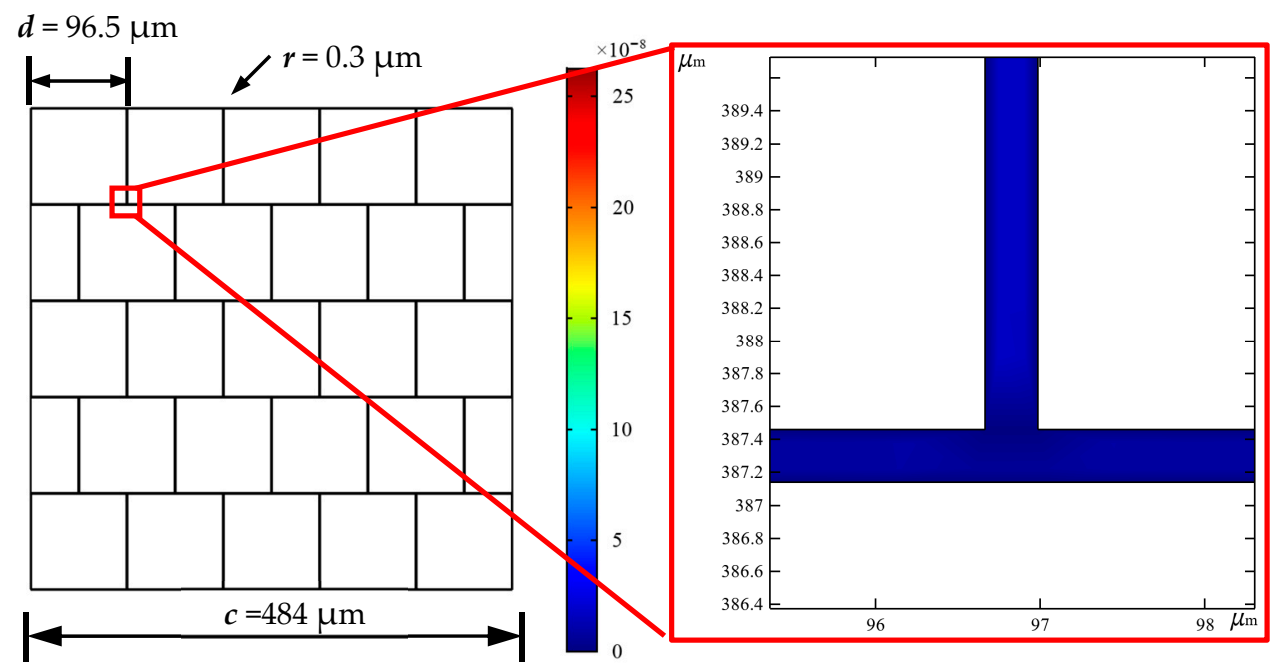

(a)

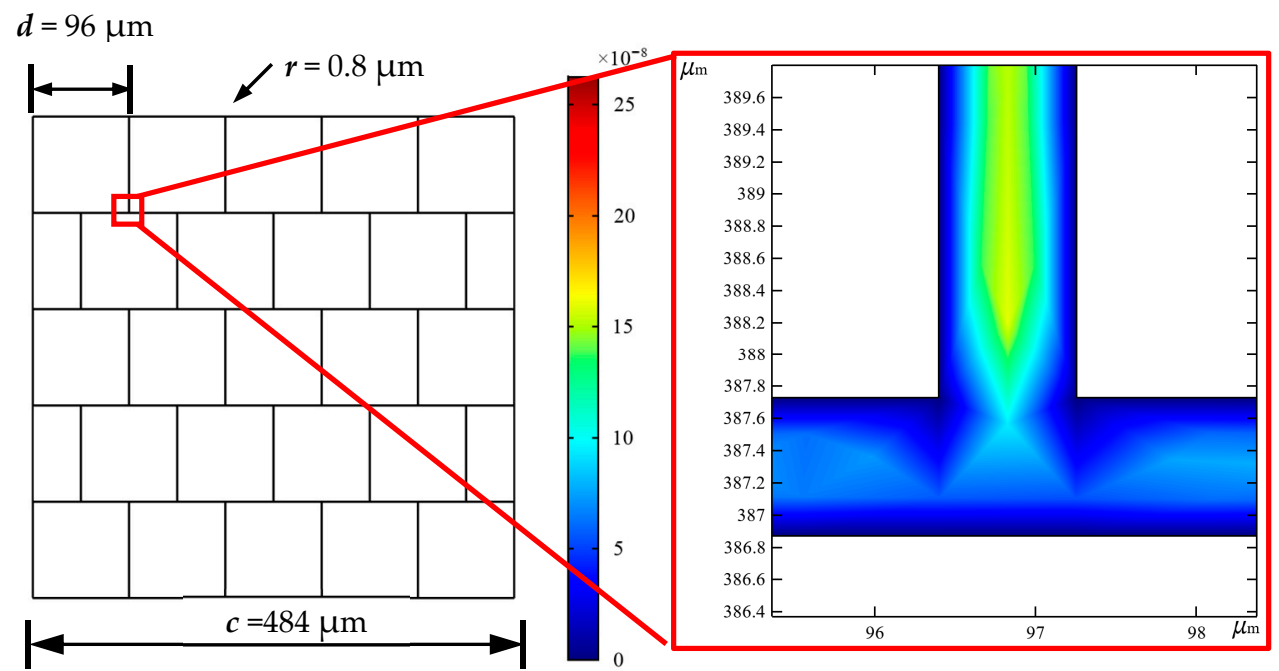

(b)

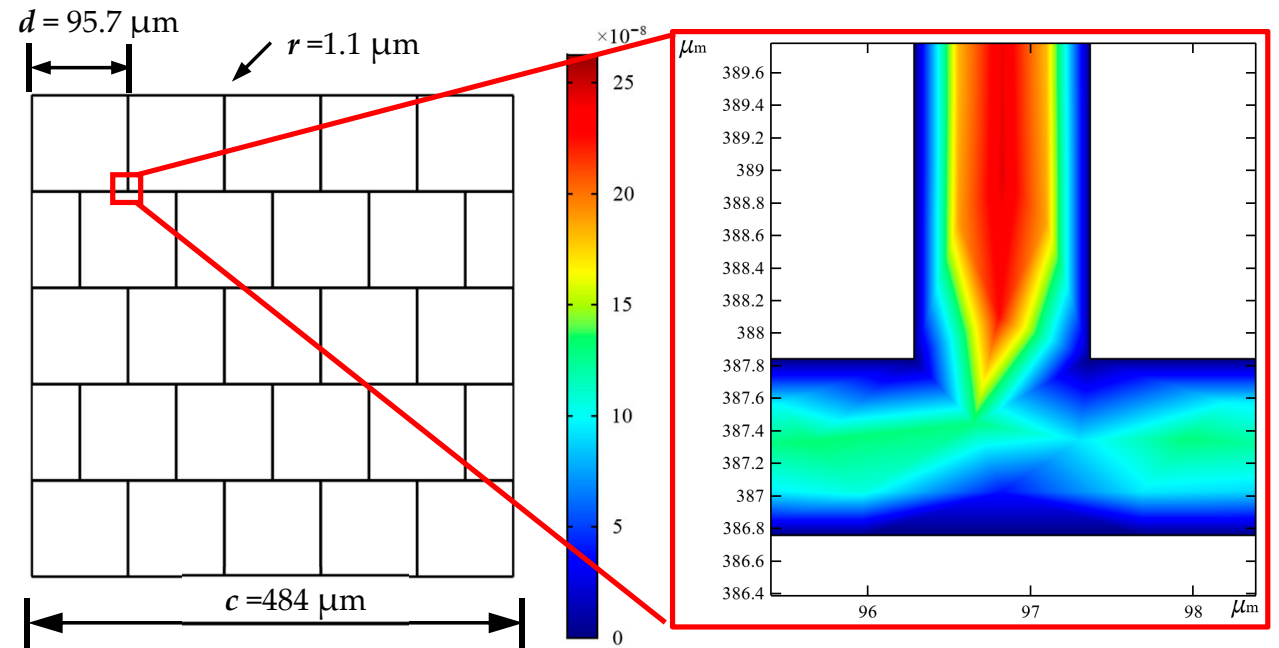

(c)

Figure 8. COMSOL model diagram (white: bentonite; Color: permeating solution). (a) $I=0.1 \mathrm{~mol} / \mathrm{L}$; $n_{\mathrm{f}}=0.012 ;(\mathbf{b}) I=0.5 \mathrm{~mol} / \mathrm{L} ; n_{\mathrm{f}}=0.0176 ;(\mathbf{c}) I=1 \mathrm{~mol} / \mathrm{L} ; n_{\mathrm{f}}=0.022$. 
As shown in Figure 8, when the ionic strength of the chemical solution is $0.1 \mathrm{~mol} / \mathrm{L}$ (the low chemical solution). The $n_{\mathrm{f}}$ is 0.012 , which can be calculated by Equation (11). Therefore, according to the COMSOL model, the final particle size and the final pore diameter of GCLs were $96.5 \mu \mathrm{m}$ and $0.3 \mu \mathrm{m}$, respectively, as shown in Figure 8a. The maximum and the average velocities were $2.23 \times 10^{-8} \mathrm{~m} / \mathrm{s}$ and $8.64 \times 10^{-9} \mathrm{~m} / \mathrm{s}$, respectively. Therefore, using this COMSOL model and Equation (3), the hydraulic conductivity, which is $2.29 \times 10^{-10} \mathrm{~m} / \mathrm{s}$ could be calculated. When the ionic strength increased to $0.5 \mathrm{~mol} / \mathrm{L}$, which represents the medium chemical solution [45], the $n_{\mathrm{f}}=0.0167$ could be calculated by Equation (11). Using this final mobile porosity, the COMSOL model, as shown in Figure 8b, could be developed. The swelling of bentonite was inhibited, and the pore size increased. The particle size decreased to $96 \mu \mathrm{m}$ while the pore size increased to $0.8 \mu \mathrm{m}$. The maximum velocity was $1.60 \times 10^{-7} \mathrm{~m} / \mathrm{s}$, and the average velocity increased to $6.18 \times 10^{-8} \mathrm{~m} / \mathrm{s}$. The average velocity in Figure $8 \mathrm{~b}$ is 7.15 times that in Figure $8 \mathrm{a}$. Accordingly, the hydraulic conductivity increased by order of magnitude, reaching $4.33 \times 10^{-9} \mathrm{~m} / \mathrm{s}$. Compared to those in Figure 8a, it is interesting that although the particle size decreased only 5\%, the final mobile porosity and the final pore size increased $150 \%$ and $170 \%$, respectively. This phenomenon confirmed that the final mobile porosity and the final pore size are the key factors affecting the hydraulic conductivity of GCLs, as hypothesized in many kinds of research $[28,46,47]$. The COMSOL models proven this mesoscopic mechanism directly. Further increased the ionic strength to $1.0 \mathrm{~mol} / \mathrm{L}$, representing a strong chemical solution [4]. As shown in Figure 8c, when the finial mobile porosity increased to 0.022 and the particle size decreased to $95.7 \mu \mathrm{m}$, the pore size and the hydraulic conductivity increased to $1.1 \mu \mathrm{m}$ and $8.7 \times 10^{-9} \mathrm{~m} / \mathrm{s}$, respectively. Comparing the changes from Figure $8 \mathrm{a}$ to Figure $8 \mathrm{c}$, it can be found that with the further increase in ionic strength, the particle size decreased $8 \%$, while the final mobile porosity and the final pore size increased $214 \%$ and $267 \%$, respectively. This indicated that with the increase in the ionic strength or the solution concentration, particle expansion was inhibited. The final pore size and the finial mobile porosity increased. The hydraulic conductivity increases with the increase in the flowable part. However, comparing the changes from Figure $8 b$ to Figure $8 c$, it can be found that when the solution increased from medium to strong, the particle size decreased only $3 \%$, the final mobile porosity and the final pore size increased $38 \%$ and $25 \%$, respectively. This indicated that when the ionic strength increased from low to medium, the changes of particle size, pore size, the final mobile porosity, and the hydraulic conductivity were obvious. However, further, increasing the ionic strength from medium to high, the changes of these parameters tend to be gentle, and the changes of hydraulic conductivity were not obvious. This was consistent with those conclusions from the experiments $[39,40]$.

\section{Predictable and the Experimental Data Comparison}

Katsumi [6] used $\mathrm{NaCl}$ solution, $\mathrm{CaCl}_{2}$ solution, and $\mathrm{KCl}$ solution to permeate powder GCLs, while Jo [48] used $\mathrm{KCl}$ solution and $\mathrm{CaCl}_{2}$ solution to permeate granular GCLs. The relevant experimental data are summarized in Table 4. Using the test data as shown in Table 4, a series of COMSOL models could be developed, as shown in Appendix A. The hydraulic conductivity of each COMSOL model could be calculated consequently using Equation (12). 
Table 4. Experimental parameter of verification.

\begin{tabular}{|c|c|c|c|c|}
\hline Literature & $\begin{array}{l}\text { Initial Particle } \\
\text { Size }\left(d_{0}\right) / \mathrm{mm}\end{array}$ & $\begin{array}{l}\text { Initial Mobile } \\
\text { Porosity }\left(n_{0}\right)\end{array}$ & $\begin{array}{l}\text { Chemical } \\
\text { Solution }\end{array}$ & $\begin{array}{l}\text { Ionic Strength } \\
(\mathrm{mol} / \mathrm{L})\end{array}$ \\
\hline \multirow{5}{*}{ Chen [44] } & \multirow{5}{*}{$1 / 0.3$} & \multirow{5}{*}{0.5} & - & 0.0395 \\
\hline & & & - & 0.0968 \\
\hline & & & - & 0.048 \\
\hline & & & - & 0.178 \\
\hline & & & - & 0.755 \\
\hline \multirow{9}{*}{ Katsumi [6] } & \multirow{9}{*}{0.075} & \multirow{9}{*}{0.4} & $0.2 \mathrm{M} \mathrm{KCl}$ & 0.10 \\
\hline & & & $0.5 \mathrm{M} \mathrm{KCl}$ & 0.25 \\
\hline & & & $1.0 \mathrm{M} \mathrm{KCl}$ & 0.50 \\
\hline & & & $0.2 \mathrm{M} \mathrm{NaCl}$ & 0.20 \\
\hline & & & $0.5 \mathrm{M} \mathrm{NaCl}$ & 0.50 \\
\hline & & & $1.0 \mathrm{M} \mathrm{NaCl}$ & 1.00 \\
\hline & & & $0.1 \mathrm{M} \mathrm{CaCl}_{2}$ & 0.10 \\
\hline & & & $0.25 \mathrm{M} \mathrm{CaCl}_{2}$ & 0.25 \\
\hline & & & $0.50 \mathrm{M} \mathrm{CaCl}_{2}$ & 0.50 \\
\hline \multirow{3}{*}{ Jo [48] } & \multirow{3}{*}{0.2} & \multirow{3}{*}{0.4} & $0.1 \mathrm{M} \mathrm{KCl}$ & 0.1 \\
\hline & & & $0.01 \mathrm{M} \mathrm{CaCl}_{2}$ & 0.06 \\
\hline & & & $0.04 \mathrm{M} \mathrm{CaCl}_{2}$ & 0.12 \\
\hline
\end{tabular}

Figure 9 shows the deviation between the predicted values and experimental values. As shown in Figure 9, the predicted hydraulic conductivity agreed well with the experimental data. Therefore, the COMSOL model can reflect the mesoscopic mechanism of chemical compatibility and predict the hydraulic conductivity of GCLs correctly.

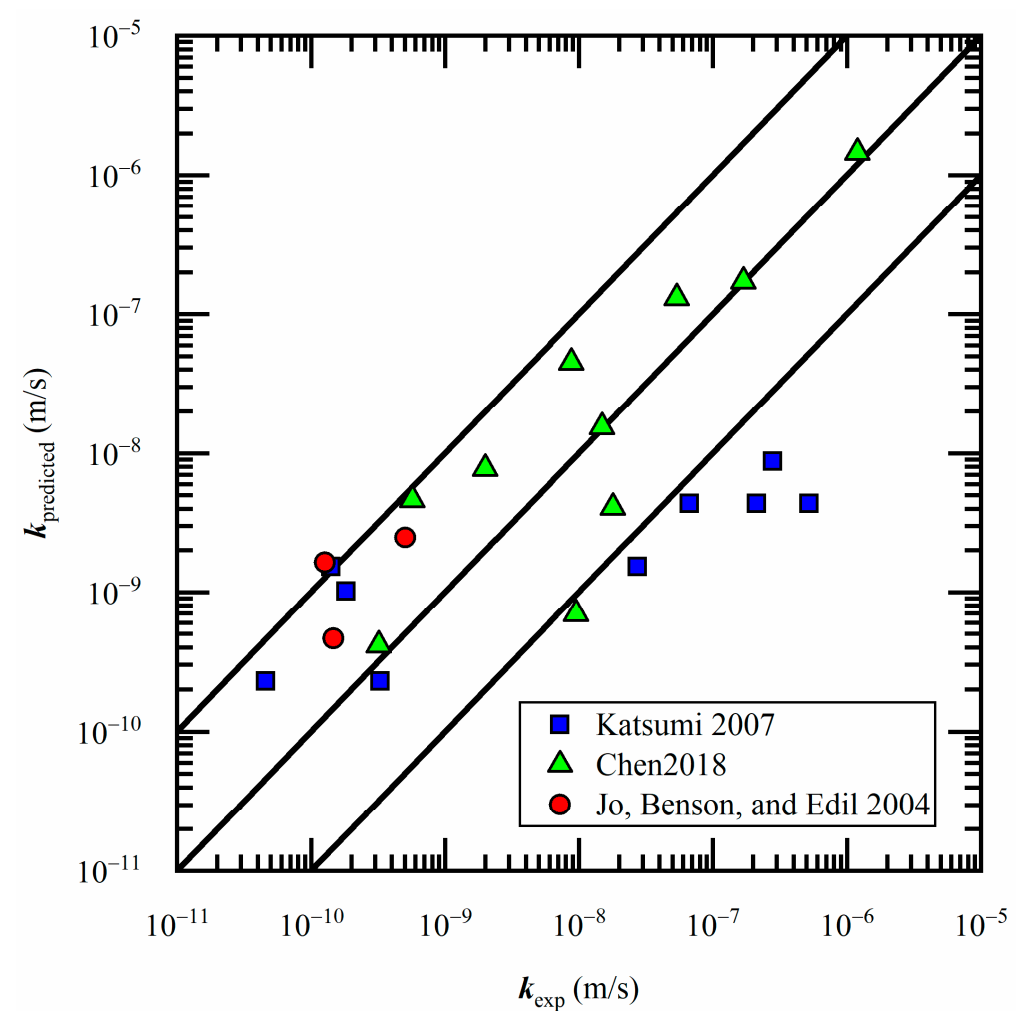

Figure 9. Comparison of predicted and experimental values.

\section{Conclusions}

The chemical compatibilities of GCLs were investigated using a COMSOL model. The mesoscopic mechanism of chemical compatibility was explored. The main conclusions were as follows: 
(1) The application of small bentonite particles and small porosity is an effective method to improve the chemical compatibility of GCLs. With the increase in the chemical solution concentration, the swelling of the bentonite particles would be suppressed.

(2) From the mesoscopic view, the final mobile porosity and the final pore size are the key factors affecting the hydraulic conductivity of GCLs. When the ionic strength increased from low to medium, the changes in particle size, the final pore size, the final mobile porosity, and the hydraulic conductivity were obvious. However, further increased the ionic strength from medium to high, the changes of these parameters tend to be gentle, and the changes of hydraulic conductivity were not obvious.

(3) Based on the numerical results, a theoretical model for predicting the hydraulic conductivity of GCLs in chemical solutions was developed. The hydraulic conductivity can be predicted by the ionic strength of the chemical solution, the initial mobile porosity, and the initial particle size.

Author Contributions: Paper writing-original draft and writing-review and editing, J.H.; methodology and formal analysis, R.S. and M.K.; Data curation, C.-X.C. and M.N. All authors have read and agreed to the published version of the manuscript.

Funding: This study was supported by the National Natural Science Foundation of China (NSFC) (Nos. 51778353, 51978390); Open Research Fund of State Key Laboratory of Geomechanics and Geotechnical Engineering, Institute of Rock and Soil Mechanics, Chinese Academy of Sciences (No. Z018007); China Scholarship Council (CSC 201906895014).

Institutional Review Board Statement: Not applicable.

Informed Consent Statement: Not applicable.

Acknowledgments: The authors express their gratitude for this financial assistance. The authors also express their sincere gratitude to Benson, the former Dean and Hamilton Chair in Engineering, School of Engineering, University of Virginia, who offered valuable suggestions for this study.

Conflicts of Interest: The authors declare no conflict of interest.

\section{Appendix A}

COMSOL models to calculate the data in Figures A1 and A2.

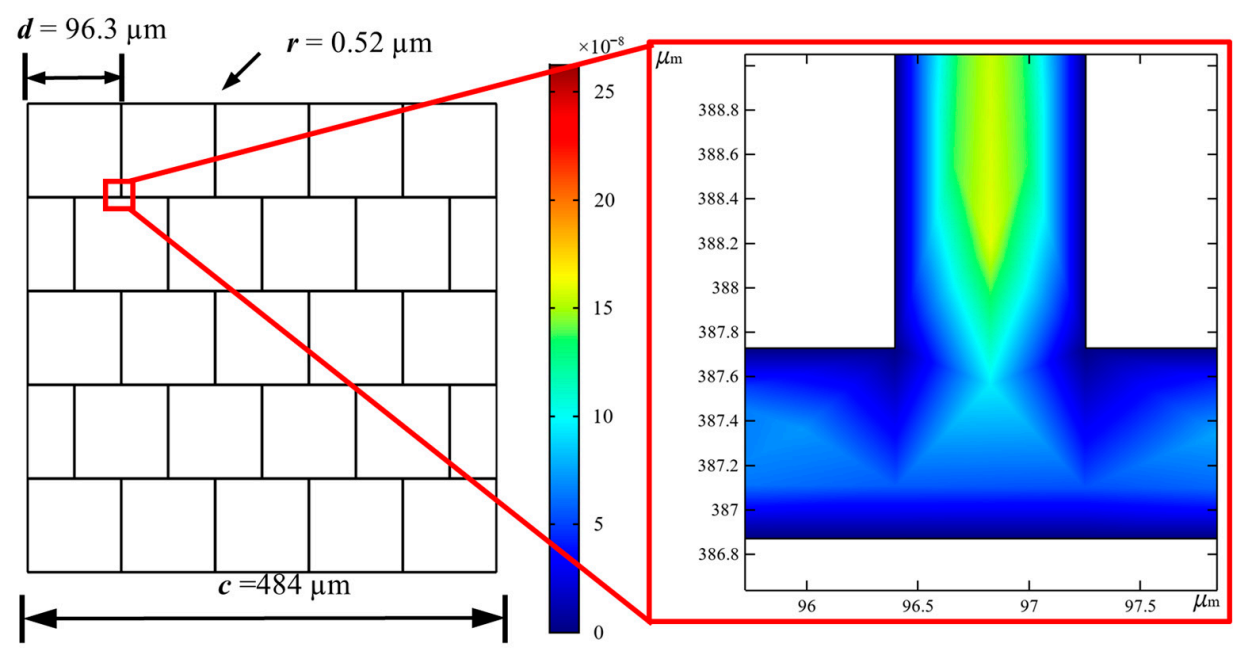

(a)

Figure A1. Cont. 


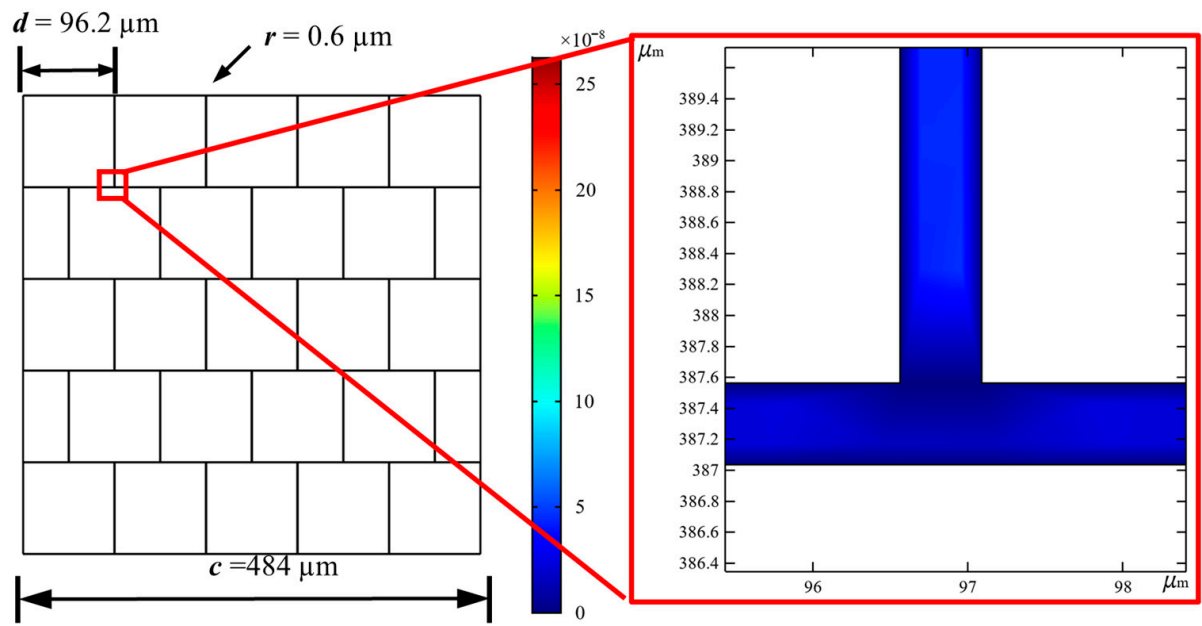

(b)

Figure A1. COMSOL model diagram using Katsumi's experimental data [6]. (a) $I=0.2 \mathrm{~mol} / \mathrm{L}$; $n_{\mathrm{f}}=0.011 ;(\mathbf{b}) I=0.25 \mathrm{~mol} / \mathrm{L} ; n_{\mathrm{f}}=0.012$.

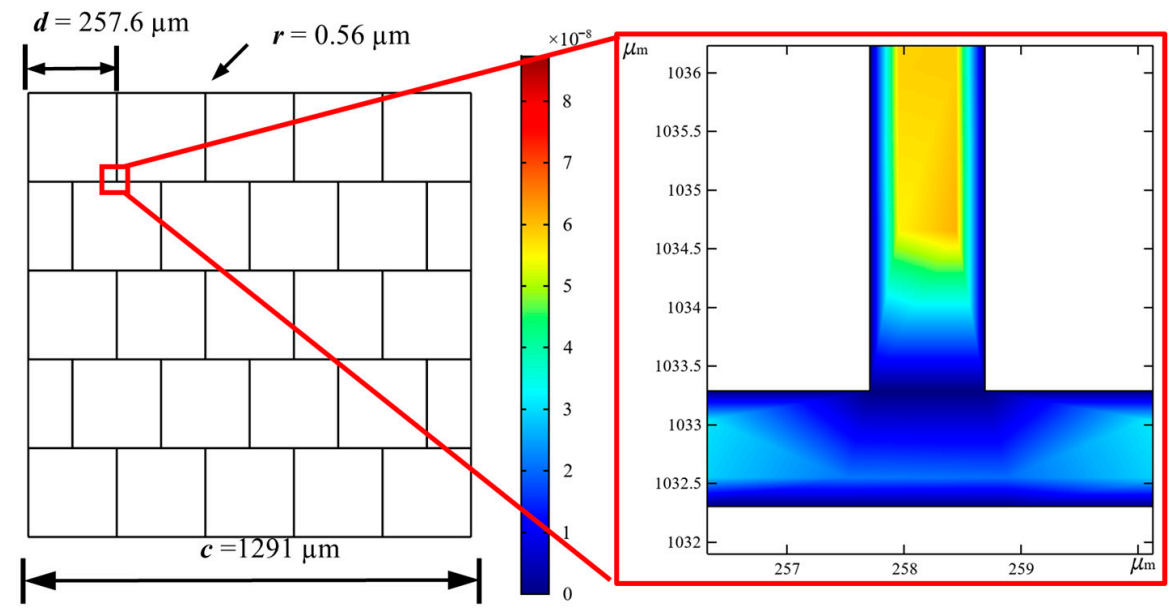

(a)

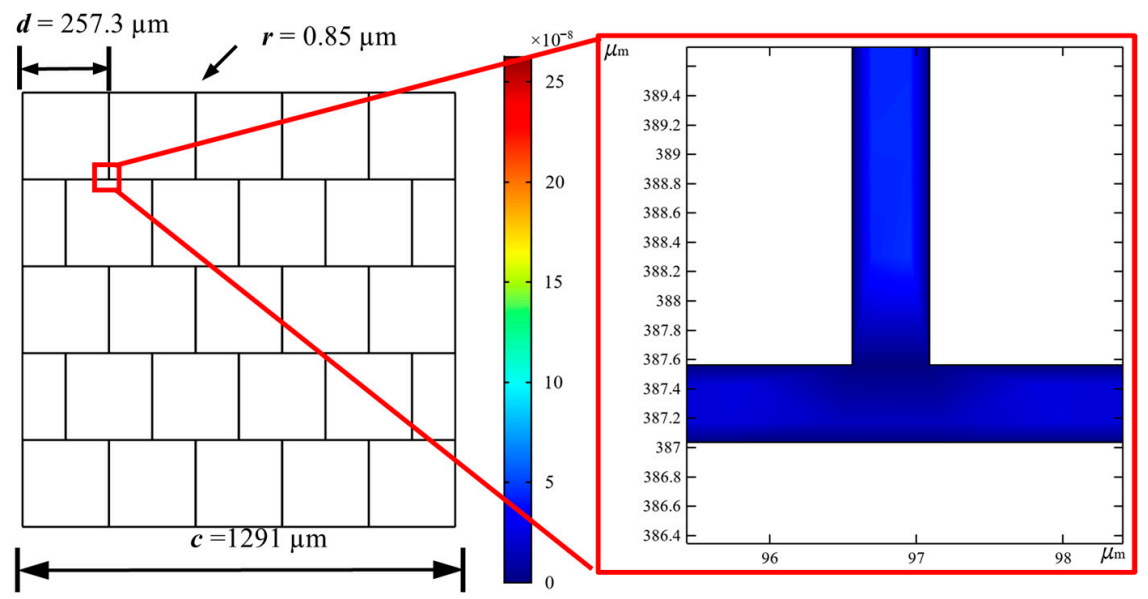

(b)

Figure A2. Cont. 


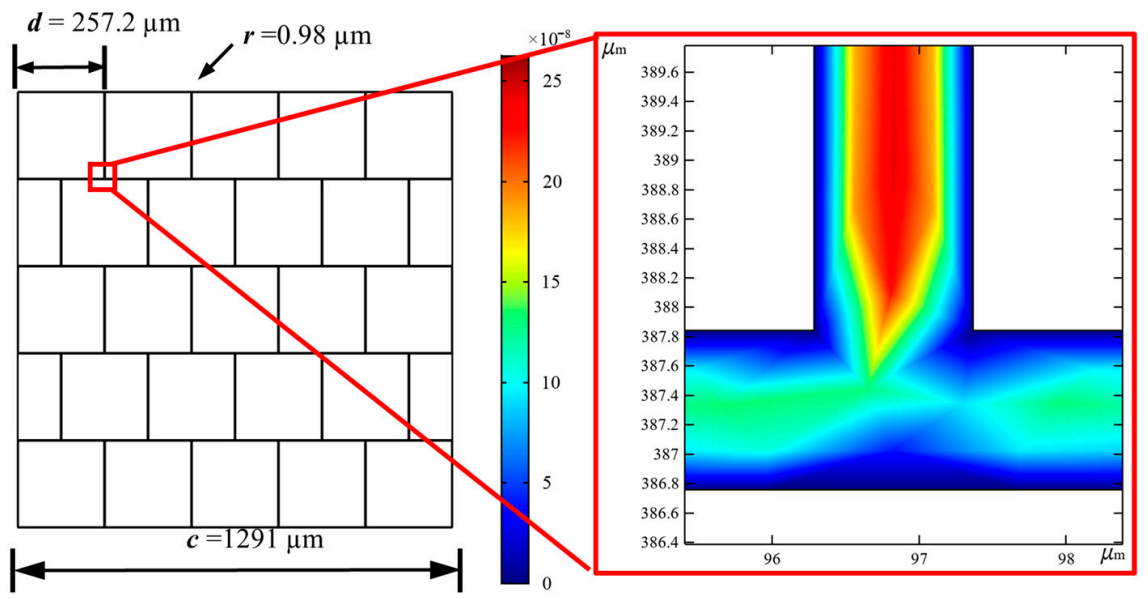

(c)

Figure A2. COMSOL model diagram using Jo's experimental data [46]. (a) $I=0.06 \mathrm{~mol} / \mathrm{L} ; n_{\mathrm{f}}=0.004$; (b) $I=0.1 \mathrm{~mol} / \mathrm{L} ; n_{\mathrm{f}}=0.007 ;(\mathbf{c}) I=0.12 \mathrm{~mol} / \mathrm{L} ; n_{\mathrm{f}}=0.008$.

\section{References}

1. Shackelford, C.D.; Benson, C.H.; Katsumi, T.; Edil, T.B.; Lin, L. Evaluating the hydraulic conductivity of GCLs permeated with non-standard liquids. Geotext. Geomembr. 2000, 18, 133-161. [CrossRef]

2. Jo, H.Y.; Katsumi, T.; Benson, C.H.; Edil, T.B. Hydraulic conductivity and swelling of nonprehydrated gcls permeated with single-species salt solutions. J. Geotech. Geoenviron. Eng. 2001, 127, 557-567. [CrossRef]

3. Kolstad, D.C.; Benson, C.H.; Edil, T.B. Hydraulic conductivity and swell of nonprehydrated geosynthetic clay liners permeated with multispecies inorganic solutions. J. Geotech. Geoenviron. 2004, 130, 1236-1249. [CrossRef]

4. Benson, C.H.; Oren, A.H.; Gates, W.P. Hydraulic conductivity of two geosynthetic clay liners permeated with a hyperalka-line solution. Geotext. Geomembr. 2010, 28, 206-218. [CrossRef]

5. Tian, K.; Benson, C.H.; Likos, W.J. Hydraulic conductivity of geosynthetic clay liners to low-level radioactive waste leachate. J. Geotech. Geoenviron. Eng. 2016, 142, 04016037. [CrossRef]

6. Katsumi, T.; Ishimori, H.; Ogawa, A.; Yoshikawa, K.; Hanamoto, K.; Fukagawa, R. Hydraulic conductivity of nonprehy-drated geosynthetic clay liners permeated with inorganic solutions and waste leachates. Soils Found 2007, 47, 79-96. [CrossRef]

7. Jo, H.Y.; Benson, C.H.; Shackelford, C.D.; Lee, J.M.; Edil, T.B. Long-term hydraulic conductivity of a geosynthetic clay liner permeated with inorganic salt solutions. J. Geotech. Geoenviron. 2005, 131, 405-417. [CrossRef]

8. Hilfer, R. Geometric and dielectric characterization of porous media. Phys. Rev. B 1991, 44, 60-75. [CrossRef]

9. Costa, A. Permeability-porosity relationship: A reexamination of the Kozeny-Carman equation based on a fractal pore-space geometry assumption. Geophys. Res. Lett. 2006, 33, L02318. [CrossRef]

10. Jang, J.; Narsilio, G.; Santamarina, J.C. Hydraulic conductivity in spatially varying media-A pore-scale investigation. Geophys. J. Int. 2011, 184, 1167-1179. [CrossRef]

11. Ahuja, L.R.; Naney, J.W.; Green, R.E.; Nielsen, D.R. Macroporosity to characterize spatial variability of hydraulic vonductivity and effects of land management. Soil Sci. Soc. Am. J. 1984, 48, 699. [CrossRef]

12. Dolinar, B.; Trček, B. A new relationship between the mobile and the adsorbed water in fine-grained soils using an effective void-ratio estimation. Bull. Eng. Geol. Environ. 2018, 78, 4623-4631. [CrossRef]

13. Ruhl, J.L.; Daniel, D.E. Geosynthetic Clay Liners Permeated with Chemical Solutions and Leachates. J. Geotech. Geoenviron. Eng. 1997, 123, 369-381. [CrossRef]

14. Liu, Y.; Bouazza, A.; Gates, W.; Rowe, R.K. Hydraulic performance of geosynthetic clay liners to sulfuric acid solutions. Geotext. Geomembr. 2015, 43, 14-23. [CrossRef]

15. Ahn, H.-S.; Jo, H.Y. Influence of exchangeable cations on hydraulic conductivity of compacted bentonite. Appl. Clay Sci. 2009, 44, 144-150. [CrossRef]

16. Mukunoki, T.; Sato, K.; Fukushima, J.; Shida, K.; Take, W. Investigating the mechanism of downslope bentonite erosion in GCL liners using X-ray CT. Geotext. Geomembr. 2018, 47, 75-86. [CrossRef]

17. Lange, K.; Rowe, R.K.; Jamieson, H.; Flemming, R.L.; Lanzirotti, A. Characterization of geosynthetic clay liner bentonite using micro-analytical methods. Appl. Geochem. 2010, 25, 1056-1069. [CrossRef]

18. Gates, W.P.; Dumadah, G.; Bouazza, A. Micro X-ray visualisation of the interaction of geosynthetic clay liner components after partial hydration. Geotext. Geomembr. 2018, 46, 739-747. [CrossRef]

19. Yan, H.; Wu, J.; Thomas, H.R.; Ding, H.; Zhan, L.; Xie, H. Analytical model for coupled consolidation and diffusion of organic contaminant transport in triple landfill liners. Geotext. Geomembr. 2021, 49, 489-499. [CrossRef] 
20. Xie, H.; Lou, Z.; Chen, Y.; Jin, A.; Zhan, T.L.; Tang, X. An analytical solution to organic contaminant diffusion through com-posite liners considering the effect of degradation. Geotext. Geomembr. 2013, 36, 10-18. [CrossRef]

21. Xie, H.; Lou, Z.; Chen, Y.; Jin, A.; Chen, P. An analytical solution to contaminant advection and dispersion through a GCL/AL liner system. Chin. Sci. Bull. 2011, 56, 811-818. [CrossRef]

22. Touze-Foltz, N.; Duquennoi, C.; Gaget, E. Hydraulic and mechanical behavior of GCLs in contact with leachate as part of a composite liner. Geotext. Geomembr. 2006, 24, 188-197. [CrossRef]

23. Guyonnet, D.; Gaucher, E.; Gaboriau, H.; Pons, C.H.; Clinard, C.; Norotte, W.; Didier, G. Geosynthetic clay liner in-teraction with leachate: Correlation between permeability, microstructure, and surface chemistry. J. Geotech. Geoenviron. 2005, 131, 740-749. [CrossRef]

24. Azad, V.J.; Li, C.; Verba, C.; Ideker, J.; Isgor, O.B. A COMSOL-GEMS interface for modeling coupled reactive-transport geochemical processes. Comput. Geosci. 2016, 92, 79-89. [CrossRef]

25. Faisal, A.A.; Ibreesam, M.M.; Al-Ansari, N.; Naji, L.A.; Naushad, M.; Ahamad, T. COMSOL multiphysics 3.5a package for simulating the cadmium transport in the sand bed-bentonite low permeable barrier. J. King Saud Univ. Sci. 2020, 32, 1944-1952. [CrossRef]

26. Pishkoo, A.; Darus, M. Using fractal calculus to solve fractal Navier-Stokes equations, and simulation of laminar static mixing in COMSOL Multiphysics. Fractal Fract. 2021, 5, 16. [CrossRef]

27. Curti, E.; Appelo, C.; Wersin, P. Modelling bentonite-water interactions at high solid/liquid ratios: Swelling and diffuse double layer effects. Appl. Clay Sci. 2004, 26, 249-257. [CrossRef]

28. Liu, J.; Song, S.; Cao, X.; Meng, Q.; Pu, H.; Wang, Y.; Liu, J. Determination of full-scale pore size distribution of Gaomiaozi bentonite and its permeability prediction. J. Rock Mech. Geotech. Eng. 2020, 12, 403-413. [CrossRef]

29. Bian, X.; Cui, Y.-J.; Li, X.-Z. Voids effect on the swelling behaviour of compacted bentonite. Geotechnique 2019, 69, 593-605. [CrossRef]

30. Ren, X.W.; Santamarina, J.C. The hydraulic conductivity of sediments: A pore size perspective. Eng. Geol. 2018, 233, 48-54. [CrossRef]

31. Gibbs, D.T.; Gates, W.P. A test method to determine expected GCL porosity under specific site conditions. In Proceedings of the 7th International Congress on Environmental Geotechnics, Melbourne, Australia, 10-14 November 2014.

32. Dachun, W.; Renquan, Z.; Yihong, S. The Basis of Hydrogeology; Geological Publishing House: Beijing, China, 1994.

33. Zhang, G.W.; Zhang, H.Y.; Wang, J.F.; Zhou, L.; Liu, P.; Jiang, X. Laboratory investigation of self-healing properties on geo-synthetic clay liners with flaw. J. Environ. Prot. Sci. 2015, 41, 53-58.

34. Jackson, R. The Dynamics of Fluidized Particles; Cambridge University Press: New York, NY, USA, 2000.

35. Ivorra, B. Application of the Laminar Navier-Stokes Equations for Solving 2D and 3D Pathfinding Problems with Static and Dynamic Spatial Constraints: Implementation and Validation in Comsol Multiphysics. J. Sci. Comput. 2017, 74, $1163-1187$. [CrossRef]

36. Zimmerman, W.B.J. COMSOL Multiphysics Modeling and Analysis with Finite Element Method; China Communications Press: Beijing, China, 2007.

37. McDowell, G.; De Bono, J. Relating Hydraulic Conductivity to Particle Size Using DEM. Int. J. Géoméch. 2021, $21,06020034$. [CrossRef]

38. Liu, Z.; Wang, K.; Liu, S.; Cai, J.; Guo, Y. Influence of freeze-thaw cycles on particle size distribution and swell index of ben-tonite in geosynthetic clay liner. J. Southeast Univ. 2015, 45, 964-968.

39. Acikel, A.S.; Gates, W.P.; Singh, R.M.; Bouazza, A.; Rowe, R.K. Insufficient initial hydration of GCLs from some subgrades: Factors and causes. Geotext. Geomembr. 2018, 46, 770-781. [CrossRef]

40. Holmboe, M.; Wold, S.; Jonsson, M. Porosity investigation of compacted bentonite using XRD profile modeling. J. Contam. Hydrol. 2012, 128, 19-32. [CrossRef] [PubMed]

41. Appelo, C. A review of porosity and diffusion in bentonite. Posiva Work. Rep. 2013, $29,2013$.

42. Lee, J.-M.; Shackelford, C.D. Impact of bentonite quality on hydraulic conductivity of geosynthetic clay liners. J. Geotech. Geoenviron. Eng. 2005, 131, 64-77. [CrossRef]

43. Scalia, J.; Benson, C.H.; Bohnhoff, G.L.; Edil, T.B.; Shackelford, C.D. Long-Term Hydraulic Conductivity of a Bentonite-Polymer Composite Permeated with Aggressive Inorganic Solutions. J. Geotech. Geoenviron. Eng. 2014, 140, 04013025. [CrossRef]

44. Chen, J.N.; Benson, C.H.; Edil, T.B. Hydraulic conductivity of geosynthetic clay liners with sodium bentonite to coal combustion product leachates. J. Geotech. Geoenviron. 2018, 144, 04018008. [CrossRef]

45. Bouazza, A.; Gates, W.P.; Abuel-Naga, H. Factors impacting liquid and gas flow through geosynthetic clay liners. Geosynth.-Recent Dev. Commem. Two Decades Geosynth. India 2006, 9, 119-146.

46. Ren, X.; Zhao, Y.; Deng, Q.; Kang, J.; Li, D.; Wang, D. A relation of hydraulic conductivity-Void ratio for soils based on Kozeny-Carman equation. Eng. Geol. 2016, 213, 89-97. [CrossRef]

47. Hong, B.; Li, X.; Wang, L.; Li, L.; Xue, Q.; Meng, J. Using the effective void ratio and specific surface area in the kozeny-carman equation to predict the hydraulic conductivity of loess. Water 2019, 12, 24. [CrossRef]

48. Jo, H.Y.; Benson, C.H.; Edil, T.B. Hydraulic conductivity and cation exchange in non-prehydrated and prehydrated bentonite permeated with weak inorganic salt solutions. Clays Clay Miner. 2004, 52, 661-679. [CrossRef] 